\title{
Annual Meeting of the Science Masters' Association
}

$\mathrm{T}$

HE thirty-fourth annual meeting of the Science Masters' Association was held at the Imperial College of Science, London, on January 2-5. More than 600 members attended.

This year's president, Mr. H. T. Tizard, Rector of the Imperial College, inaugurated the proceedings, after the annual dinner, with an address on "Science and the Industrial Depression". He referred to the gloomy picture of the immediate future envisaged by Dr. Norwood in his presidential address two years ago, and how it had been justified by succeeding events. There was a widespread belief that science contributed to industrial depression in creating unemployment by substituting the machine for the man, in discouraging skill by replacing skilled work by unskilled work, and in promoting discord by increas ing the powers for evil. The last, however, was a moral question, the decision to use the powers of science for good or evil being dependent upon education.

Mr. Tizard denied that it was true that the progress of science tended to discourage skill; what it had really done was to replace one skill by others. In the matter of increase of unemployment, figures were given for both England and the United States to show that mechanisation actually increased the number of wage earners between 1914 and 1927. The responsibility for industrial depression lay with the economist and politician rather than with scientific workers.

It was possible, however, that because of the inertia of industry in times of prosperity, continuous advantage was not taken of new inventions and discoveries of science. Consequently, a set-back, due to whatever slight cause, would put into operation widespread economies, and sudden application of scientific labour-saving devices that would give rise to the unemployment of many workers who, however, were really superfluous to industry, even in times of prosperity. The coal industry was given as an example.

To overcome this industrial apathy towards the application of science, it was necessary for science to be added to the mental equipment of administrators, possibly by a combination of science and economics at the universities. Moreover, it was the duty of all science masters not only to imbue the gifted few of their pupils with the spirit of intellectual adventure, but also to impart to many the power of observation and the skill of hand that bring interest and happiness to life, and to send all out into the world with a sense of fact and a sense of law.

Prof. E. N. da C. Andrade in his lecture on new experimental work in sound, dealt with the phenomena associated with Chladni's plate, Kundt's tube and the sensitive flame, and showed by ingeniously simple experiments new facts that could only be explained by new theories. In particular, the vortex theory, which explained the phenomena of Kundt's tube, made possible very accurate measurement of the velocity of sound. It was found that the velocity of sound did in some measure depend upon the frequency and that previously noticed but ignored irregularities in the velocity of sound in the work of other investigators were of significance.

The nature of heavy hydrogen and heavy water was the main feature of interest in Prof. H. V. A.
Briscoe's lecture on recent advances in chemistry. The nomenclature of the new hydrogen, and its isolation by electrolysis, fractional distillation, or fractional diffusion through palladium were described. The properties of heavy water, f.p. $3 \cdot 8^{\circ} \mathrm{C}$, b.p. $101 \cdot 4^{\circ} \mathrm{C}$, density $1 \cdot 1056$, temperature of maximum density $11 \cdot 6^{\circ}$, its 50 per cent greater viscosity and its biological effects excited great interest, as did the discussion of the theoretical implications in the matter of atomic structure.

Dr. Allan Ferguson provided a most interesting lecture on London's contributions to science, ranging backwards from Lord Rayleigh, Clerk Maxwell, Faraday, Wollaston, Young, Cavendish and Halley, to Wren and even Chaucer. The biographical details of these celebrities were supplemented by interesting historical exhibits.

The evening lecture on January 3 was devoted to fungi, by Mr. J. Ramsbottom, who, starting from yeast and its influence on life's necessities, beer, bread and cheese, proceeded, with the aid of beautifully coloured slides, to demonstrate the difference between edible and poisonous fungi.

Very interesting experiments capable of school demonstration, and therefore doubly valuable to the science masters, were shown on January 4 by $\mathrm{Mr}$. $\mathrm{H}$. Haile, in his lecture on the polarisation of light and its application to applied science. This was followed by a lecture by Prof. A. Brammall on geochemistry applied to the genetic study of 'hybrid' rock typesa compact summary of useful information. In the evening, the Astronomer Royal, Dr. H. Spencer Jones, summarised the modern views on the structure of the universe, illustrating his discourse by striking astronomical photographs, particularly of the Milky Way. There was a further lecture on January 5 by Prof. R. A. Fisher on adaptation and mutations.

It has always been a feature of the annual meeting of the Science Masters' Association for members to exhibit and demonstrate with home-made apparatus new technique, methods and notions developed in the school laboratories. Many of these are now found in the "Science Masters' Book", published by the Association. This year, the members' exhibition was larger than ever, and full of stimulating ideas. A gramophone record used to reflect light, giving rise to interference fringes, 'Cellophane' as a semi-permeable membrane, milk bottles as gas jars, soap bubbles blown in an enclosed space so that they may drain undisturbed in order to demonstrate colours of thin films, were among the striking features.

There was a much appreciated innovation this year in that Mr. F. A. Meier was invited to give a lecture demonstration on some of his ingeniously simple experiments, which obviously delighted the lecturer as well as the audience. With the aid of toy trucks, thermos flasks, home-made springs, football bladders, balloons, bicycle wheels, pickaxes, flour bins, he demonstrated principles of mechanics, hydrostatics, properties of matter, light, heat, electricity and magnetism. Moreover, these experiments were quantitative, and Mr. Meier was able to show that it was usually possible to obtain at least a one per cent accuracy.

In addition to these lectures, there were two important discussions, one on the School Certificate 
biology syllabus, and the other on the elementary science suggested by the School Certificate Investigators' Report as a compulsory subject at the School Certificate stage. This latter discussion will form the subject of a further report.

Visits were paid by various members to seventeen factories and Government scientific institutions in and around London. These included, among others, the Courtauld Institute of Biochemistry, the Paint
Research Station, Government Laboratories, the Royal Observatory, the Royal Aircraft Establish. ment, and the Royal College of Surgeons. These, together with the exhibition of scientific textbooks and apparatus, made a very full programme. Twenty. three publishers and thirty-nine manufacturers and thirty-five members exhibited.

The next annual meeting will be at Oxford under the presidency of Dr. N. V. Sidgwick. F. W. T.

\section{Annual Meeting of the Mathematical Association}

$\mathrm{T}^{\mathrm{H}}$ HE annual meeting of the Mathematical Association was held at the Institute of Education, London, W.C.1, on January 4-5, under the presidency of Prof. G. N. Watson. Discussions on the place of mathematics in the new central schools, on the interesting and novel suggestion that in the teaching of elementary geometry, solid geometry should precede plane geometry, and on the place of differentials in the teaching of the calculus, showed that the Association has not forgotten its primary purpose, the improvement-if necessary, the reform - of the teaching of elementary mathematics.

Under the title "Scraps from some Mathematical Note-Books", Prof. Watson delivered a lucid and stimulating presidential address. It was based on the diary in which C. F. Gauss (1777-1855), one of the greatest mathematicians of all time, recorded many of his discoveries; Gauss started keeping this diary at the age of nineteen, and it is remarkable that the majority of the hundred and fifty entries were made before 1801 .

The first entry is the discovery of the possibility of a ruler and compass construetion of the regular polygon of seventeen sides, a particular case of a more general problem to which Gauss himself gave a complete answer at a slightly later date. There are several entries referring to the quadratic reciprocity theorem; another, prefaced by a triumphant "Eureka", is equivalent to the result that every integer of the form $8 m+3$ is expressible as the sum of three odd squares. Other entries mentioned by Prof. Watson deal with continued fractions, the zeros of a Bessel function, and a function which is connected with the famous zeta function of Riemann. In connexion with this last entry, Prof. Watson pointed out that in a copy of Schulze's logarithm tables inscribed "Gauss, 1791", Gauss has made a note which can readily be interpreted as a statement that the number of primes less than a large number $x$ is approximately equal to $x / \log _{e} x$; this is the "prime number theorem", of which the first proofs were given by Hadamard and de la Vallée Poussin in 1896.

In addition to describing these striking results, Prof. Watson gave a brief account of the developments to which these results have led, concluding with a description of some remarkable numerical work connected with the prime number theorem which was carried out in 1933. His general aim was not only to honour Gauss but also to stress the importance to mathematicians of the dictum of N. H. Abel (1802-29) who, when asked how he had been able to accomplish so much in so short a time, replied: "By studying the masters, not the pupils".

Prof. E. H. Neville, professor of mathematics in the University of Reading, has been elected president of the Association for the forthcoming year.

\section{Research at the Cawthron Institute}

$\mathrm{T}$ HE Cawthron Institute at Nelson, New Zealand, was founded and endowed through the munificence of Mr. Thomas Cawthron, who was born in 1833, and after his death his trustees decided that a research institute for the investigation of agricultural problems should be established as the best means of carrying out his expressed desire. The Cawthron centenary lecture, "The Achievements of the Cawthron Institute", delivered on October 9 by Prof. T. H. Easterfield on his retirement from the directorship of the Institute, formed a fitting epilogue to the first Cawthron lecture, "The Aims and Ideals of the Cawthron Institute", given by him in 1917.

Beginning with the early work of the Institute, Prof. Easterfield said that one of the first problems to be attacked was the improvement of the fruit industry. A soil survey of the Nelson provinee was initiated, and the distribution and special characteristics of the soils studied with particular reference to fruit growing. The information thus gained led to recommendations with regard to soil treatment and cover cropping without which many orchardists would have been obliged to abandon their crops. Biological problems such as bitter-pit, black spot, woolly aphis and codlin moth were investigated concurrently. An insect, Aphelinus mali, was imported in 1920 for the control of woolly aphis and induced to breed in New Zealand. Its remarkable success is evidenced by the fact that it is no longer necessary to spray trees which formerly had suffered heavily. Such parasitic control is being extended with promising results to other insect and plant pests including the blowfly, which attacks lambs, and the piri-piri, a burr-producing plant which seriously reduces the commercial value of wool fleece. Much useful work has been done in controlling fungus diseases of fruit and flowers. In the work on black-spot, the main fungal disease of pip fruit, it has been found that infection can be controlled by spraying at a period, varying with the season, when ascospores are just about to be ejected by the fallen leaves of the previous year.

Prof. Easterfield gave further instances of researches which have resulted in outstanding increases in the production of fruit and other important crops, notably the control of brown rot in peaches, the improved fertilising of raspberries, the selection of soils for tobacco and lucerne, the steam sterilisation 